\title{
Subjective Experiences of Bipolar Patients in The Residual or Remitted Phase
}

\author{
Soo Hyun Joe* \\ Department of Psychiatric rehabilitation, Bugok National Hospital, Korea
}

*Corresponding author: Soohyun Joe, Department of Psychiatric rehabilitation, Bugok National Hospital, Changnyung-kun, Kyungnam, Korea

\begin{abstract}
ARTICLE INFO
Received: 慧 February 04, 2019

Published: 蔧 February 19, 2019
\end{abstract}

Citation: Soo Hyun Joe. Subjective Experiences of Bipolar Patients in The Residual or Remitted Phase. Biomed J Sci \& Tech Res 14(5)-2019. BJSTR. MS.ID.002602.

Abbreviations: K-FBF: Korean Version Of Frankfurter Beschwerde Fragebogen; SCL-90-R: Symptom Check List 90-R, PANSS: Positive And Negative Symptoms Scales; YMRS: Young Mania Rating Scale; MADRS: Montgomery Asberg Depression Rating Scale; GSI: Global Severity Index (Standardized Total Score) Of The Symptom Check List 90-R (SCL-90-R); COPE: Coping Responses; ATTN: Selective Attention; LANG: Language Disorder; COFL: Cognitive Floating; PERC: Perceptual Disorder; ANXI: Specific Anxiety; BLOC: Blocking Symptoms; AUTO: Automatic Behavior Disorder; DSCR: Deterioration of Discrimination; PSMO: Psychomotor Disorder

\section{ABSTRACT}

Aim: Patients with bipolar disorder often experience subtle impairment in residual or remitted phase although they do not show florid mood or psychotic symptom any more. This study investigated subjective experiences of bipolar patients during residual or remitted state.

Methods: Sixty patients (29 males, 31 females) who were determined to be in remission or residual state from the acute phase were included in this study. All patients were assessed in two dimensions: subjective experiences and objective experiences. Subjective experiences were measured with the Korean version of the Frankfurter Beschwerde-Fragebogen (K-FBF) and Symptom Check List 90-R (SCL-90-R). Objective psychopathology was measured with the Positive and Negative Symptoms Scale (PANSS), Young Mania Rating Scale (YMRS), and Montgomery Asberg Depression Rating Scale (MADRS). We then examined the relationship between subjective experiences and objective psychopathology.

Results: A longer period of hospitalization was significantly correlated with lower K-FBF and SCL-90-R total scores. The K-FBF total score was not correlated with YMRS and PANSS scores. However, the SCL-90-R total score was significantly correlated with almost all objective psychopathology measures. Multiple regression analysis revealed that the subjective expereince $\backslash$ as measured by the total K-FBF score was predicted by the number of previous episodes.

Conclusion: It is suggested that subjective experience of cognitive impairment is more trait dependent than state dependent in bipolar disorder. It is also suggested that subjective experiences are aggravated with the number of episodes, and hence it might be related to brain damage as the illness progresses.

\section{Introduction}

Traditionally, objective psychopathology has been considered more valid than self-reported assessments, and so subjective experience has received little attention [1,2]. Although there is some concern about methodological problems of subjective experience [3], there is evidence that even patients with poor insight can recognize their symptoms and report truthfully [4]. Especially bipolar patients usually obtain good insight once the acute phase is remited, so evaluation of subjective experience is considered to be relia ble in the detection of cognitive impairment. Subjective experience is sensitive to measure the subtle cognitive impairments that are not yet psychotic [5]. Although it contributes to the improvement of inter-rater reliability, the diagnostic system used currently - based on objective pathology - does not offer new perspective on etiology and psychopathology. We therefore need to pay careful attention to areas that are difficult to evaluate using objective measurements. There have been reports that subjective experience exists even 
before distinct objective psychopathology has occurred [6,7], and some authors have suggested subjective experience as a marker of vulnerability that is related to organic brain abnormality [8-10]. In summary, it is expected that the investigation of subjective cognitive impairment in bipolar disorder would be helpful in elucidating the pathophysiology and etiology of bipolar disorder.

Several instruments have been used to evaluate subjective experiences: Subjective Deficit Syndrome Scale2, Subclinical Symptoms Scale [11], Bonn Scale for the Assessment of Basic symptoms [12] and Frankfurter Beschwerde Fragebogen (FBF) [13]. Among these, the FBF is one of the most representative tools and is the most widely used in Europe. FBF measures subjective complaint of cognitive impairment in psychotic disorder. Unlike the Symptom Check List 90-R (SCL-90-R), which covers general subjective symptoms, FBF points to cognitive impairment specifically. In spite of some concerns of the validity of self-reported assessments3, FBF is known to be a reliable measure of subjective cognitive impairment $[8,10]$. Specifically, FBF evaluates residual symptoms and the remission period well $[1,14]$, and hence can be an effective instrument for investigating subjective cognitive impairment during the residual and remitted phases. This study investigated the implication of cognitive impairment of bipolar patients by measuring FBF in the residual and remitted phases. We also examined the relationship between clinical characteristics, objective psychopathology, general subjective dysfunction, and subjective experience. To exclude the influence of acute symptoms on cognitive function, we performed evaluations when the acute symptoms were judged to be either remitted or only residual.

\section{Material and Methods}

\section{Subjects}

This study was performed at the Department of Psychiatric rehabilitation of Bugok National Hospital, Kyungnam, Korea. Bugok National Hospital is one of [15] national mental hospital and special ward for rehabilitation in which residual or remitted patients with schizophrenia is usually admitted. One hundred and twenty bipolar I disorder patients who were consecutively admitted between May 2018 and July 2018 were screened for this study. Patients were diagnosed separately by two senior psychiatrist using DSM-IV criteria at the time of discharge, and only bipolar I disorder patients were included. To avoid diagnostic uncertainties relating to the spectrum of schizophrenia, patients who had psychotic periods without mood symptoms or mood-incongruent psychotic symptoms were excluded. We also excluded the patients who refused to fill out questionnaire, who had a history of organic mental disorder including systemic lupus erythematosus (SLE) psychosis, or who had existing substance abuse including alcohol. These criteria lead to the final sample consisting of 60 inpatients (29 males, 31 females). At the evaluation, all of the patients were taking mood stabilizers and most of them were taking atypical antipsychotics. The assessment was performed when the subjects were remitted from the acute phase (i.e., in the residual or remitted phase), since it was necessary for them to cooperate but not necessarily be symptom free. All patients gave their informed consent to participate in the study.

\section{Assessment}

Subjective cognitive impairments were assessed using the Korean version of FBF (K-FBF)15. The K-FBF has 10 phenomenological areas regarding Specific Anxiety (ANXI), Selective Attention (ATTN), Deterioration of Discrimination (DSCR), Psychomotor Disorder (PSMO), Perceptual Disorder (PERC), Cognitive Floating (COFL), Blocking Symptoms (BLOC), language disorder (LANG), Automatic Behavior Disorder (AUTO), Coping Responses (COPE). K-FBF contains 103 items, with each item consisting of the following 5-point response scale:
i. strongly disagree
i. disagree
ii. undecided
iii. agree and
iv. strongly agree

We defined a positive response as a score of each K-FBF item of higher than 3 . We calculated the positive response rate by dividing the total positive response by the number of items in each subscale multiplied by the number of total subjects. Clinical assessments were performed by one of the authors. We gathered data on illness characteristics such as the number of episodes, duration of illness, and family history from patient interviews and medical records. Objective psychopathology was assessed using the following scales: Positive and Negative Symptoms Scale (PANSS), Young Mania Rating Scale (YMRS), and Montgomery Asberg Depression Rating Scale (MADRS). General subjective symptoms were measured using the SCL-90-R. All evaluations were performed by the same psychiatrist on the same day. Additionally, we used item 12 in the PANSS general symptoms scale for the measurement of insight [16].

\section{Statistics}

Independent sample t-test was used to examine the differences between groups, each of which is defined by YMRS and MADRS. A two-step Pearson correlation analysis was used. First, we did correlation analysis between demographic data and K-FBF standardized total score. So, we examined the relationship between demographic data and subjective cognitive impairment. And with these results, in the second analysis, we used significantly correlated demographic data as a covariate. Second correlation analysis was done between objective psychopathology (i.e. YMRS, MADRS, PANSS scores) and K-FBF. Additionally, correlation analysis between general subjective symptom (SCL-90-R) and K-FBF was performed to detect the difference of evaluation domain between SCL-90-R and K-FBF. Multiple regression analysis was performed to predict subjective cognitive impairment from a number of variables : sex, age, education years, employment, family history of affective disorder in the first degree relatives, combined psychotic feature, age at onset, duration 
of illness, number of previous episode, period of hospitalization, YMRS score, MADRS score, PANSS positive, negative, general symptom scores and total score were used as independent variables and $\mathrm{K}-\mathrm{FBF}$ was used as the dependent variable. Statistical analyses were performed using SPSS (version 12.0 for Windows).

\section{Results}

Among the 60 patients at discharge, 56 patients were diagnosed as bipolar I disorder with manic episode and 4 patients as bipolar, I disorder with depressive episode. There is no patient who was diagnosed as mixed episode. The characteristics of the patient samples are summarized in Table 1 . Males had a statistically significant longer duration of illness $(\mathrm{p}=0.036)$ and lower MADRS score $(\mathrm{p}=0.039), \mathrm{K}-\mathrm{FBF}$ standardized total score $(\mathrm{p}=0.031)$, and SCL-90-R total score $(\mathrm{p}=0.038)$. We found that YMRS and PANSS scores did not differ significantly with sex. Frequent and less frequent positively responsed items are listed in Table 2 . The most frequent positively responsed item was item 58. Item 21 and 91 were followed then. The least two frequent positive responsed items were item 26, 37. There are 10 subscales in K-FBF, and each subscales of K-FBF consists of different number of items. We calculated response rate of each subscales Table 3. It indicates that COPE, ATTN, and LANG had the higher response rates. The lowest response rate was observed for PSMO, followed by DSCR. The mood statuses (mania or hypomania, euthymia, and depressed) of the patients are reported in Table 4. Euthymia was defined as an endpoint YMRS total score $\leq 1217$ and MADRS as $\leq 9$ [18].

Table 1: Demographic and clinical characteristics of the patients.

\begin{tabular}{|c|c|c|c|}
\hline Variables & Male & Female & Total \\
\hline & $29(48.3 \%)$ & $31(51.7 \%)$ & $60(100 \%)$ \\
\hline Age (year) & $34.4 \pm 13.5$ & $35.1 \pm 12.8$ & $34.8 \pm 13.0$ \\
\hline Education (year) & $13.9 \pm 2.8$ & $12.9 \pm 3.3$ & $13.4 \pm 3.1$ \\
\hline Age at onset (year) & $26.2 \pm 11.7$ & $31.8 \pm 12.6$ & $29.1 \pm 12.4$ \\
\hline No. of previous episodes & $3.1 \pm 2.6$ & $3.3 \pm 5.4$ & $3.2 \pm 4.2$ \\
\hline Duration of illness (month) & $106 \pm 109$ & $55.7 \pm 67.2 *$ & $79.8 \pm 92.7$ \\
\hline period of hospitaliza- & $3.3 \pm 3.4$ & $2.6 \pm 3.1$ & $3.0 \pm 3.3$ \\
\hline tion(month) & $15(45.7 \%)$ & $20(64.5 \%)$ & $35(58.3 \%)$ \\
\hline Unemployed & $2(6.9 \%)$ & $3(9.7 \%)$ & $5(8.3 \%)$ \\
\hline $\begin{array}{c}\text { Family history of affective } \\
\text { disorder }\end{array}$ & $18(62.1 \%)$ & $24(77.4 \%)$ & $42(70 \%)$ \\
\hline Combined psychotic features & $34.2 \pm 14.7$ & $44.9 \pm 22.2 *$ & $39.7 \pm 13.0$ \\
\hline K-FBF (standardized total) & $12.6 \pm 4.72$ & $13.7 \pm 5.08$ & $13.1 \pm 4.9$ \\
\hline PANSS positive symptoms & $8.93 \pm 2.19$ & $8.68 \pm 1.58$ & $8.8 \pm 1.9$ \\
\hline PANSS negative symptoms & $19.8 \pm 3.33$ & $19.9 \pm 3.21$ & $19.9 \pm 3.2$ \\
\hline PANSS global symptoms & $19.8 \pm 1.4 \pm 7.49$ & $42.4 \pm 9.28$ & $42.0 \pm 8.4$ \\
\hline PANSS total & $13.9 \pm 11.1$ & $16.6 \pm 11.3$ & $15.3 \pm 11.2$ \\
\hline YMRS & $3.5 \pm 4.43$ & $5.68 \pm 3.75 *$ & $4.6 \pm 4.2$ \\
\hline MADRS & $44.1 \pm 11.2$ & $51.8 \pm 16.3 *$ & $48.1 \pm 14.5$ \\
\hline GSI & & & \\
\hline * $<0.05$ & & \\
\hline & & & \\
\hline & & & \\
\hline
\end{tabular}

Table 2: Frequent and less frequent positive response items of K-FBF.

\begin{tabular}{|c|c|c|c|}
\hline \multicolumn{2}{|r|}{ Item of K-FBF } & \multicolumn{2}{|c|}{ Positive Response } \\
\hline & Frequent positive response & $N$ & $\%$ \\
\hline Item 21 & $\begin{array}{l}\text { I often cannot differentiate correctly } \\
\text { between noises and hear everything as } \\
\text { if it were mixed together. }\end{array}$ & 19 & 31.67 \\
\hline Item 58 & $\begin{array}{l}\text { These days I always feel tense. So, I'm } \\
\text { concerned about everything despite my } \\
\text { attempts not to be concerned. }\end{array}$ & 19 & 31.67 \\
\hline Item 44 & $\begin{array}{l}\text { I often stop my movement during } \\
\text { performance and have to think what to } \\
\text { do next. }\end{array}$ & 17 & 28.33 \\
\hline \multirow[t]{2}{*}{ Item 91} & $\begin{array}{l}\text { I try to work as slow as possible, other- } \\
\text { wise my thoughts are perturbed. }\end{array}$ & 17 & 28.33 \\
\hline & Less frequent positive response & $\mathrm{N}$ & $\%$ \\
\hline Item 16 & $\begin{array}{c}\text { I always feel unpleasant, so I cannot } \\
\text { differentiate between pleasant and } \\
\text { unpleasant feelings. }\end{array}$ & 3 & 5 \\
\hline Item 51 & $\begin{array}{c}\text { Sometimes I feel as if the surrounding } \\
\text { objects are moving or being shaken, } \\
\text { so I have to stand still or sit and calm } \\
\text { down. }\end{array}$ & 3 & 5 \\
\hline Item 72 & $\begin{array}{l}\text { Even the music that I've heard before } \\
\text { sounds strange. }\end{array}$ & 3 & 5 \\
\hline Item 26 & I'm too nervous to go out of the house. & 2 & 3.33 \\
\hline Item 37 & $\begin{array}{l}\text { Often, I'm scared when someone walks } \\
\text { across or talks behind me. }\end{array}$ & 2 & 3.33 \\
\hline
\end{tabular}

Table 3: The response rate of each subscale sorted by the response rate.

\begin{tabular}{|c|c|c|c|}
\hline Subscale & $\begin{array}{c}\text { Total Positive } \\
\text { Response }\end{array}$ & $\begin{array}{c}\text { No. Of Items in } \\
\text { Each Subscale }\end{array}$ & $\begin{array}{c}\text { Response Rate of } \\
\text { Subscale (\%) }\end{array}$ \\
\hline COPE & 140 & 11 & 12.7 \\
\hline ATTN & 96 & 8 & 12 \\
\hline LANG & 91 & 9 & 10.1 \\
\hline COFL & 79 & 8 & 9.9 \\
\hline PERC & 106 & 13 & 8.2 \\
\hline ANXI & 73 & 9 & 8.1 \\
\hline BLOC & 68 & 10 & 7.6 \\
\hline AUTO & 75 & 6 & 7.5 \\
\hline DSCR & 43 & 10 & 6.6 \\
\hline PSMO & 66 & 9 & \\
\hline
\end{tabular}

Table 4: Mood state of the patients.

\begin{tabular}{|c|c|c|c|c|}
\hline Mood state & Criteria & Male & Female & Total \\
\hline \multirow{2}{*}{ Manic or hypomanic } & YMRS $>12$ & \multirow{2}{*}{$15(12)$} & \multirow{2}{*}{$17(12)$} & \multirow{2}{*}{$32(24)$} \\
\hline & MADRS $\leq 9$ & & & \\
\hline \multirow{2}{*}{ Euthymic } & YMRS $\leq 12$ & \multirow{2}{*}{$13(5)$} & \multirow{2}{*}{$11(9)$} & \multirow{2}{*}{$24(14)$} \\
\hline & MADRS $\leq 9$ & & & \\
\hline \multirow{2}{*}{ Depressed } & YMRS $\leq 7$ & \multirow{2}{*}{$1(1)$} & \multirow{2}{*}{$3(3)$} & \multirow{2}{*}{$4(4)$} \\
\hline & MADRS $>9$ & & & \\
\hline Total & & $29(18)$ & $31(24)$ & $60(42)$ \\
\hline
\end{tabular}


The clinical characteristics in the manic or hypomanic group and the euthymic group are compared in Table 5. There were no significant differences in age, years of education, age at onset, hospitalized period, and number of previous episodes between the two groups. The euthymic group showed a significantly longer duration of illness and lower MADRS score, PANSS positive, general subscale core, PANSS total score, and SCL-90-R global score. The euthymic group also showed significantly better insight than the manic or hypomanic group. However, there was no significant difference in K-FBF standardized scores between the two groups.

Table 5: Differences between the manic or hypomanic group and the euthymic group.

\begin{tabular}{|c|c|c|c|}
\hline & Manic or Hypomanic Group & Euthymic Group & 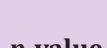 \\
\hline & $N=32$ & $N=24$ & $p$-value \\
\hline $\operatorname{Sex}(M / F)$ & $17 / 15$ & 13-Nov & 0.787 \\
\hline Age (years) & $33.2 \pm 14.3$ & $34.6 \pm 10.8$ & 0.691 \\
\hline Education (years) & $13.6 \pm 3.1$ & $12.8 \pm 3.2$ & 0.392 \\
\hline Age at onset (years) & $29.8 \pm 13.4$ & $26.1 \pm 10.0$ & 0.264 \\
\hline Duration of illness (months) & $55.7 \pm 55.6$ & $109 \pm 118$ & 0.047 \\
\hline Hospitalized period (months) & $2.3 \pm 2.7$ & $3.5 \pm 3.5$ & 0.162 \\
\hline No. of previous episodes & $3.3 \pm 5.3$ & $3.1 \pm 2.6$ & 0.845 \\
\hline $\begin{array}{l}\text { No. of first-degree relatives with } \\
\text { affective disorder }\end{array}$ & $0.13 \pm 0.3$ & $0.04 \pm 0.2$ & 0.256 \\
\hline YMRS & $24.3 \pm 6.7$ & $5.4 \pm 4.4$ & $<0.001$ \\
\hline MADRS & $5.5 \pm 2.1$ & $1.6 \pm 2.1$ & $<0.001$ \\
\hline PANSS positive symptoms & $17.0 \pm 2.9$ & $8.9 \pm 2.1$ & $<0.001$ \\
\hline PANSS negative symptoms & $9.0 \pm 1.2$ & $8.4 \pm 2.2$ & 0.246 \\
\hline PANSS global symptoms & $21.5 \pm 2.8$ & $17.5 \pm 2.2$ & $<0.001$ \\
\hline PANSS total & $47.8 \pm 5.9$ & $34.8 \pm 4.8$ & $<0.001$ \\
\hline Insight (PANSS G12) & $3.7 \pm 1.9$ & $1.8 \pm 1.2$ & $<0.001$ \\
\hline K-FBF standardized total & $43.8 \pm 20.8$ & $34.0 \pm 18.2$ & 0.073 \\
\hline GSI & $52.9 \pm 16.9$ & $41.2 \pm 8.4$ & 0.001 \\
\hline
\end{tabular}

Among the subscales of K-FBF, only PERC showed significant differences between the manic or hypomanic group and the euthymic group. The euthymic group showed a significantly lower score than the manic or hypomanic group $(\mathrm{p}=0.02)$ (data not shown). We did not compare the depressive group with the other groups because the sample size was too small to produce statistically meaningful results. We compared the groups with psychotic symptoms and without psychotic symptoms. We found no significant difference between the two groups in age, years of education, age at onset, duration of illness, hospitalized period, number of previous episodes, number of affective disorder in first-degree relatives, YMRS score, PANSS subscale scores and total scores, and insight. Only the MADRS score was significantly higher in the group with psychotic symptoms $(\mathrm{p}=0.02)$. There was no significant difference in K-FBF subscale scores and standardized total score between the two groups $(p<0.05)$. The results of the correlation analysis of demographic data, YMRS score, MADRS score, PANSS positive, negative, general subscale score, PANSS total score, SCL90-R global score, and K-FBF total score are reported in Tables 6 \& 7. Except for hospitalized period $(R=-0.26, p=0.04)$, there was no significant correlation between demographic data and K-FBF total score and SCL-90-R total score Table 6. After controlling for hospitalized period, K-FBF total score was significantly correlated with MADRS and SCL-90-R global score Table 7. There was no significant correlation between PANSS scores and K-FBF. There was a statistically significant correlation between SCL-90-R global score and all scales used in this study except for the PANSS negative symptoms score. There was no significant correlation between between K-FBF standardized total score and patient insight i.e., PANSS general item 12 Table 7. SCL-90-R standardized total score was significant correlated with patient insight Table 7 . In the multiple regression analysis, there is no significance with sex, age, with or without psychotic symptoms, employment, education, age at onset, duration of illness, YMRS score, MADRS score, PANSS subscale scores each other. But we adjusted those variables because they can influence the cognitive impairment Table 8. The subjective cognitive impairment as measured by the total K-FBF score was significantly predicted by hospitalized period (beta $=-0.39, \mathrm{p}=0.02$ ) and the number of previous episodes (beta=0.35, $\mathrm{p}=0.02$ ); it explained $39.6 \%$ of the variance (adjusted R2=0.17). 
Table 6: The correlation between demographic variables and K-FBF standardized total score and SCL-90-R global score index $(n=60)$.

\begin{tabular}{|c|c|c|c|c|}
\hline & \multicolumn{2}{|c|}{ K-FBF Total Score } & \multicolumn{2}{c|}{ SCL-90-R Total Score } \\
\cline { 2 - 5 } & $\mathbf{R}$ & $\mathbf{p}$ & $\mathbf{R}$ & $\mathbf{p}$ \\
\hline Age (year) & 0.056 & 0.67 & 0.14 & 0.3 \\
\hline Education (year) & 0.074 & 0.57 & 0.002 & 0.99 \\
\hline Age at onset (year) & 0.18 & 0.16 & 0.24 & 0.06 \\
\hline $\begin{array}{c}\text { Duration of illness } \\
\text { (month) }\end{array}$ & -0.19 & 0.14 & -0.20 & 0.13 \\
\hline $\begin{array}{c}\text { Period of hospitalization } \\
\text { (month) }\end{array}$ & -0.26 & 0.04 & -0.26 & 0.04 \\
\hline $\begin{array}{c}\text { Number of previous } \\
\text { episodes }\end{array}$ & 0.2 & 0.12 & 0.24 & 0.07 \\
\hline $\begin{array}{c}\text { No. of first-degree } \\
\text { relatives with affective } \\
\text { disorder }\end{array}$ & -0.055 & 0.68 & -0.04 & 0.76 \\
\hline
\end{tabular}

Table 7: Partial correlations between K-FBF total score and other scales controlling for hospitalized period.

\begin{tabular}{|c|c|c|c|c|}
\hline \multirow{2}{*}{} & \multicolumn{2}{|c|}{ K-FBF Total Score } & \multicolumn{2}{c|}{ SCL-90-R Total Score } \\
\cline { 2 - 5 } & $\mathbf{R}$ & $\mathbf{p}$ & $\mathbf{R}$ & $\mathbf{p}$ \\
\hline YMRS & 0.2 & 0.13 & 0.46 & $<0.001$ \\
\hline MADRS & 0.31 & 0.02 & 0.39 & $<0.01$ \\
\hline $\begin{array}{c}\text { PANSS positive } \\
\text { symptoms }\end{array}$ & 0.14 & 0.29 & 0.36 & $<0.01$ \\
\hline $\begin{array}{c}\text { PANSS negative } \\
\text { symptoms }\end{array}$ & 0.25 & 0.05 & 0.2 & 0.14 \\
\hline $\begin{array}{c}\text { PANSS general } \\
\text { symptoms }\end{array}$ & 0.17 & 0.2 & 0.29 & 0.03 \\
\hline PANSS total score & 0.17 & 0.2 & 0.38 & $<0.01$ \\
\hline SCL-90-R total score & 0.55 & $<0.001$ & & \\
\hline Insight (PANSS G12) & 0.09 & 0.51 & 0.326 & 0.01 \\
\hline
\end{tabular}

Table 8: Multiple regression analysis of subjective cognitive impairment measured by K-FBF total score.s

\begin{tabular}{|c|c|c|}
\hline & B & $\boldsymbol{p}$-value \\
\hline Sex & 0.19 & 0.19 \\
\hline Age (years) & -0.24 & 0.77 \\
\hline With psychotic symptoms & 0.18 & 0.21 \\
\hline Employment & -0.06 & 0.62 \\
\hline Education (years) & 0.19 & 0.2 \\
\hline Age at onset (years) & 0.29 & 0.72 \\
\hline Duration of illness (months) & 0.06 & 0.91 \\
\hline Hospitalized period (months) & -0.39 & 0.02 \\
\hline No. of previous episodes & 0.35 & 0.02 \\
\hline No. of first-degree relatives with affective disorder & -0.11 & 0.41 \\
\hline YMRS & 0.36 & 0.22 \\
\hline MADRS & 0.02 & 0.92 \\
\hline PANSS positive symptoms & -0.29 & 0.33 \\
\hline PANSS negative symptoms & 0.28 & 0.1 \\
\hline PANSS global symptoms & 0.02 & 0.92 \\
\hline Dependent variable: K-FBF total score & \\
\hline Adjusted R ${ }^{2}=0.17$ & \\
\hline
\end{tabular}

\section{Discussion}

There were no statistically significant differences in the K-FBF score between the euthymic patient's group and the manic or hypomanic patients' group, which provides additional support that subjective cognitive impairment persists even in a euthymic state, i.e., the residual or remitted phase. This also suggests that it is relatively unaffected by mood state and objective psychotic symptoms. There was also no significant difference in the K-FBF scores between the group with psychotic features and that without psychotic features. The K-FBF score was also not correlated with PANSS and YMRS scores. From these two findings, we hypothesize that subjective cognitive impairment is more trait dependent than state dependent in bipolar disorder. Huber was the first to employ subjective symptoms to investigate the etiology and pathophysiology of psychotic disorder $[17,18$,$] . A British group subsequently studied subjective$ cognitive impairment in schizophrenics [6, 7]. They found that subjective cognitive impairment is present long before the onset of definite psychotic symptoms and suggested an organic etiology for them. Also, several authors have viewed subjective cognitive impairments as phenomenological indexes of vulnerability [19-20]. The K-FBF standardized total score was strongly positively correlated with SCL-90-R global score but was not correlated with YMRS and PANSS scores. SCL-90-R was moderately correlated with YMRS and weakly correlated with PANSS positive, general symptoms, and total scores. The SCL-90-R comprises psychotic symptoms overlapping partially with PANSS and overall subjective symptoms including subjective cognitive impairment. However, the correlation between K-FBF and SCL-90-R was stronger than between PANSS and SCL-90-R, which suggests that the correlations between different scales are more influenced by the form of reporting than by the actual contents of the scales.

Patients have a tendency to have better insight as they feel sick more to their subjective symptoms. Subjective symptom measured by K-FBF is somewhat different from what measured by SCL-90-R. SCL-90-R contains vegetative symptom and more general items compare to K-FBF. Patients have more insight into their disease as they feel more symptoms subjectively. On the other hand, K-FBF deals with nearly only cognitive domain. Usually measuring K-FBF requires some cognitive ability to realize and report patient's own disability and discomfort. More cognitively impaired, K-FBF score is expected to be elevated but the ability of monitoring and gaining insight of patient's own impairment was also disturbed. Therefore K-FBF score was not correlated significantly with insight. The number of previous episodes is known to be a predictor of poor outcome and cognitive impairment in bipolar disorder [21-23]. In our study, K-FBF scores were predicted from a higher number of previous episodes, which is consistent with previous studies. This suggests that subjective cognitive impairment worsens with the number of episodes, and hence it might be related to brain damage as the illness progresses. Future studies should investigate the relationship between structural brain abnormality and subjective cognitive impairment. 
A shorter hospitalized period predicted a higher K-FBF score, which might be explained by longer hospitalized patients being more severely withdrawn or more confused by their psychotic symptoms. This would lead to an impaired ability to report subjective impairments. However, when we compared the longer and shorter hospitalized patients' groups, we did not find the evidence of more severe withdrawal in the longer hospitalized patients' group. Moreover, the longer hospitalized group showed lower manic symptoms and positive psychotic symptoms. Therefore, another factor not shown in these data might influence longer hospitalized patient, which is supported by multiple regression analysis excluding these longer hospitalized patients that showed that only the number of previous episodes predicted the K-FBF score. Possible factors influencing the longer hospitalized group are pharmacotherapy and psychosocial interventions. Further study is needed to consider the influence of such interventions. In this study, the COPE and ATTN subscales of K-FBF showed relatively high response rates, and the PSMO and DSCR subscales showed relatively low positive response rates. The COPE subscale measures the effort of patients to protect themselves from psychopathology-related perturbations and to reduce functional impairments. Such a coping response is divided into two types: evasive behavior and compensatory behavior. Representative evasive behaviors are "I often leave the place when there is much traffic or noise around me" (item 61) and "I avoid meeting people because I don't understand them well” (item 93), and representative compensatory behaviors are "I always strive to pull my thoughts together" (item 35) and "I try to work as slow as possible, otherwise my thoughts are perturbed" (item 91). Psychotic patients are known to exhibit tendencies to be avoidant, socially withdrawn, and to give up easily [24,25]. These ineffective coping responses are formed in the early years of life and comprise a facet of pathological personality [19]. They are also often observed in patients with affective disorder. The ATTN subscale evaluates the tendency to use selective attention more intensively. It compensates for a lack of appropriate attentional allocation to a particular task. Psychotic patients frequently complain that they are overwhelmed with more stimuli than they can cope with [6], resulting in them becoming bewildered and retreating. Patients attempt to overcome this by using selective attention. Many studies have demonstrated that attention deficit is one of the most pronounced cognitive impairments among patients with unipolar and bipolar affective disorders [20-22]. One of these studies indicated that intentional processes of response selection and control were significantly impaired, whereas sensory selective attention was largely unaffected [26]. This dissociation between these two attention factors may explain the high ATTN response rate of bipolar affective disorder. Bipolar patients appear to make an effort to compensate for their pervasive attention impairment with the relatively preserved selective attention domain. This finding also supports the hypothesis that attentional impairment is at the core of the neurocognitive deficit associated with bipolar affective disorders [27].
The DSCR subscale evaluates the confusion of internal and external stimuli or anhedonia (item 87, 52, 23). Psychotic patients often exhibit poor reality testing and confuse internal fantasy and the real world. Definite psychotic symptoms, hallucinations, and delusions seem related to this subscale, and this phenomenon is observed in more acute, highly disturbed patients. This might explain why patients in the residual or remitted phase in our study showed relatively low DSCR score. The PSMO subscale evaluates psychomotor control. Typical PSMO items are "sometimes my arms and legs move spontaneously without my intention" (item 9), "sometimes I feel as if my body is floating" (item 18), and "sometimes I feel as if the surrounding objects are moving or being shaken, so I have to stand still or sit and calm down" (item 51). Several studies have shown that bipolar patients have psychomotor dysfunction [28,29]. However, in our study this was experienced less than the other cognitive domains. Among the subscales of K-FBF, only PERC showed a higher score in the manic or hypomanic patients' group than in the euthymic patient's group. PERC measures visual and auditory perceptional distortions, so it is related to vivid psychotic symptoms, hallucinations, and delusions. Therefore, the manic or hypomanic patients' group might have more vivid psychotic symptoms than the euthymic patient's group, and the PERC subscale might be less trait dependent than the other subscales in K-FBF.

This study has several limitations. First, the samples were from an inpatient population, and hence may have represented a more severe group and hence not be representative of the general population of those with residual and remitted bipolar disorder. Second, this study had a cross-sectional design. Long-term stabilized patients might show different profiles of subjective experience, and hence future longitudinal studies should clarify if subjective experience is trait dependent or state dependent. Third, the effect of medication was not controlled. The inclusion of medication-free patients is required to establish whether cognitive impairment is related to illness and not to medication. However, drug-free bipolar patients are rarely found in a clinical situation.

\section{Conclusion}

This study results suggest that subjective experience of patients with bipolar disorder is more trait dependent than state dependent.

\section{References}

1. Peralta V, Cuesta MJ (1994) Subjective experiences in schizophrenia A critical review. Compr Psychiatry 35(3): 198-204.

2. Jaeger J, Bitter I, Czobor P, Volavka J (1990) The measurement of subjective experience in schizophreniaThe Subjective Deficit Syndrome Scale. Compr Psychiatry 31(3): 216-226.

3. Williams RM, Alagaratnam W, Hemsley DR (1984) Relationship between subjective self-report of cognitive dysfunction and objective informationprocessing performance in a group of hospitalized schizophrenic patients. Eur Arch Psychiatr Neurol Sci 234(1): 48-53.

4. van den Bosch RJ, Rombouts RP, van Asma MJ (1993) Subjective cognitive dysfunction in schizophrenic and depressed patients. Compr Psychiatry 34(2): 130-136. 
5. Parnas J, Handest, P,Saebye, D,Jansson L (2003) Anomalies of subjective experience in schizophrenia and psychotic bipolar illness. Acta Psychiatr Scand 108(2): 126-133.

6. McGhie A, Chapman J (1961) Disorders of attention and perception in early schizophrenia. Br J Med Psychol 34: 103-116.

7. Chapman J (1966) The early symptoms of schizophrenia. Am J Psychiatry 112(484): 225-251.

8. Huber G (1982) Psychosen Diagnostik Basissymptome und biologische Parameter. Weissenauer Schizophrenie-Symposion. Stuttgart, Schattauer.

9. Mundt C KS (1987) Zur Schizophrenies pezifitat von negativen und Basissymptomen. Nervenarzt 58: 489-495.

10. Stanghellini G QL, Ricca V, Strik WK, Cabras PL (1991) Basic symptoms and negative symptoms in the light of language impairment. Compr Psychiatry 32(2): 141-146.

11. Petho B, Bitter I (1985) Types of complaints in psychiatric and internal medical patients. Psychopathology 18(5-6): 241-253.

12. Gross G, Huber G, Klosterkotter J, Linz M (1987) Bonner Skala fur die Beurteilung von Basissymptomen. Springer Berlin.

13. Sullwold L (1986) Frankfurter Beschwerde-Fragebogen (3); In: sullwold L, Huber G (Eds.), Schizophrene Basisstorungen. Springer Berlin.

14. Ricca V, Galassi F, La Malfa G, Mannucci, E,Barciulli E, (1997) Assessment of basic symptoms in schizophrenia, schizoaffective and bipolar disorders. Psychopathology 30: 53-58.

15. Hwan Il Chang, Jung Kyu Kim, Tae Ho Yun, Ji Young Song, Doh Joon Yoon, et al. (1995) Manual of Kyung Hee-Frankfurter Beschwerde Fragebogen. J Korean Neuropsychiatr Assoc 34: 754-770.

16. Lysaker PH, Bryson GJ, Lancaster RS, Evans JD, Bell MD, et al. (2003) Insight in schizophrenia: associations with executive function and coping style. Schizophr Res 59(1): 41-47.

17. Tohen M, Waternaux CM, Tsuang MT (1990) Outcome in Mania. A 4-year prospective follow-up of 75 patients utilizing survival analysis. Arch Gen Psychiatry 47(12): 1106-1111.

\section{ISSN: 2574-1241}

DOI: 10.26717.BJSTR.2019.14.002602

Soohyun Joe. Biomed J Sci \& Tech Res

This work is licensed under Creative

Commons Attribution 4.0 License

Submission Link: https://biomedres.us/submit-manuscript.php
18. Zimmerman M, Posternak MA, Chelminski I (2004) Defining remission on the Montgomery-Asberg depression rating scale. J Clin Psychiatry 65(2): 163-168.

19. Stabenau J PW (1968) Comparative life history differences of families of schizophrenic's delinquents and normal. Am J Psychiatry 124: 15261534

20. O Carroll RE RA, Lawrie SM, A Rogers, C Murray (1995) Laterality of visuospatial attention in acute and chronic schizophrenia, major depression and in healthy controls. Psychol Med 25(5): 1091-1095.

21. Suffin SC EW (1995) Neurometric subgroups in attentional and affective disorders and their association with pharmacotherapeutic outcome. Clin Electroencephalogr 26(2): 76-83.

22. Cohen R, Lohr I, Paul R, Boland R (2001) Impairments of attention and effort among patients with major affective disorders. J Neuropsychiatry Clin Neurosci 13(3): 385-395.

23. Martinez Aran A, Vieta E, Colom F, Reinares M, Benabarre A, et al. (2000) Cognitive dysfunctions in bipolar disorder: evidence of neuropsychological disturbances. Psychother Psychosom 69(1): 2-18.

24. Quraishi S, Frangou S (2002) Neuropsychology of bipolar disorder: a reviewJ Affect Disord. 72(3): 209-226.

25. Martinez Aran A, Vieta E, Reinares M, Colom F, Torrent C, et al. (2004) Cognitive function across manic or hypomanic, depressed, and euthymic states in bipolar disorder. Am J Psychiatry 161(2): 262-270.

26. Huber G (1983) The concept of substrate-close basic symptoms and its significance for the theory and therapy of schizophrenic diseases. Nervenarzt 54(1): 23-32.

27. Van Gorp WG, Altshuler L, Theberge DC, Wilkins J, Dixon W, et al. (1998) Cognitive impairment in euthymic bipolar patients with and without prior alcohol dependence. A preliminary study. Arch Gen Psychiatry 55(1): 41-46.

28. Kessing LV (1998) Cognitive impairment in the euthymic phase of affective disorder. Psychol Med 28(5): 1027-1038.

29. Ferrier IN, Thompson Jill M (2002) Cognitive impairment in bipolar affective disorder implications for the bipolar diathesis. British journal of psychiatry 180(4): 293-295

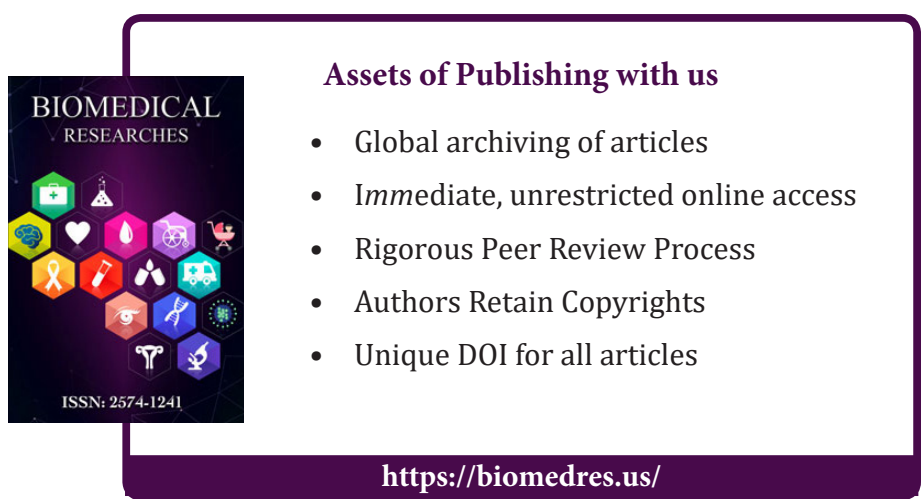

